\title{
Long-term results of the REV (réparation à l'ètage ventriculaire) operation
}

\author{
Duccio Di Carlo, MD, ${ }^{\mathrm{a}}$ Biagio Tomasco, MD, ${ }^{\mathrm{b}}$ Laurence Cohen, $\mathrm{MD},{ }^{\mathrm{c}}$ Pascal Vouhé, $\mathrm{MD},{ }^{\mathrm{c}}$ and \\ Yves Lecompte, $\mathrm{MD}^{\mathrm{c}}$
}

\begin{abstract}
Objective: Despite its innovative features, the réparation à l'ètage ventriculaire (REV) procedure has not gained large popularity in the treatment of transposition of the great arteries, ventricular septal defect, pulmonary stenosis, and related anomalies, and thus the Rastelli operation remains the preferred type of repair. We try to obviate the alleged lack of long-term results that has been suggested to explain this reluctance to change.
\end{abstract}

\begin{abstract}
Methods: We reviewed a series of 205 patients who underwent the REV procedure between 1980 and 2003.
Results: Hospital mortality was $12 \%$ (24 patients). Ten of 181 early survivors residing in distant countries could not be traced for follow-up. There were 13 late deaths ( 2 of noncardiac causes). Overall survival and freedom from any reoperation at 25 years were $85 \%$ and $45 \%$, respectively, as determined by using the Kaplan-Meier method. Reoperation was commonly required because of recurrent right ventricular outflow tract obstruction (36 patients) and rarely by left ventricular outflow tract stenosis (3 patients). By using cumulative method analysis, at the 25 -year follow-up interval, the probability of being alive without reoperation was $45 \%$, that of reoperation for right ventricular outflow tract obstruction was $33 \%$, and that of reoperation for left ventricular outflow tract obstruction was 5\%. Clinical status is excellent: 137 patients are in New York Heart Association class I (87\%), and 131 patients are free of arrhythmias.
\end{abstract}

Conclusions: These results represent a considerable improvement over those of the Rastelli operation in terms of survival and need for reoperation for right or left ventricular outflow tract obstruction. (J Thorac Cardiovasc Surg 2011;142:336-43)

Anomalies of the ventriculoarterial connection with subpulmonary stenosis are often indicated with acronyms, such as transposition of the great arteries (TGA), double-outlet right ventricle $(\mathrm{RV})$, double-outlet left ventricle $(\mathrm{LV})$, and Taussig-Bing anomaly, and are treated classically by using the Rastelli operation. ${ }^{1}$ In our clinical practice, for the sake of simplification, we have chosen to group all these anomalies under the term malposition of the great arteries, taking as a unifying element the essential need for surgical repair to establish a connection between the LV and the aorta and an unobstructed pathway from the RV to the pulmonary artery. The operation described by Lecompte and colleagues $^{2}$ in 1980 , termed réparation à l'ètage ventriculaire (REV), by including the reconnection of the aortic valve with the LV through a ventricular septal defect (VSD) endorses the principle of the Rastelli operation. Here, though,

From the Department of Pediatric Cardiac Surgery, ${ }^{a}$ Ospedale Pediatrico Bambino Gesù, Rome, Italy; the Department of Cardiovascular Surgery, ${ }^{\mathrm{b}}$ Unità Operativa di Cardiologia Pediatrica, Ospedale San Carlo, Potenza, Italy; and the Department of Pediatric Cardiac Surgery, ${ }^{\mathrm{c}}$ University Paris Descartes and Sick Children Hospital, Paris, France.

Disclosures: Authors have nothing to disclose with regard to commercial support.

Received for publication April 28, 2010; revisions received Sept 23, 2010; accepted for publication Oct 24, 2010; available ahead of print Jan 31, 2011.

Address for reprints: Duccio Di Carlo, MD, Ospedale Pediatrico Bambino Gesù, Piazza Sant'Onofrio 4, 00165 Rome, Italy (E-mail: ducciodicarlo@mac.com).

$0022-5223 / \$ 36.00$

Copyright (c) 2011 by The American Association for Thoracic Surgery

doi:10.1016/j.jtcvs.2010.10.041 similarity between the 2 procedures ends: resection of the conal septum (to avoid the spiral shape of the LV-to-aorta tunnel) and direct reimplantation of the pulmonary trunk on the RV (to prevent the need for a complete tubular prosthesis) are unique features of the REV procedure. By using this technique, anatomic repair could be an option for a greater number of patients.

The early results of the REV procedure have been reported in detail. ${ }^{3-8}$ Because it has been claimed that its long-term results are unclear, a study was undertaken to fill this vacuum of scientific knowledge.

\section{MATERIALS AND METHODS}

Two hundred five patients with malposition of the great arteries, VSD, and left ventricular outflow tract obstruction (LVOTO) underwent operations performed by 2 of the authors (Y.L. and P.V.) between 1980 and 2003; the median age at the time of the REV procedure was 1.7 years (range, $0.3-16$ years), and 93 (45\%) patients were younger than 2 years. Twenty-four patients died during the operation and are excluded from further analysis. One hundred eighty-one $(88 \%)$ patients survived and are the subject of this study; their median age at the time of the operation was 1.8 years (range, $0.35-16$ years).

\section{Diagnosis}

Along with our terminology, ${ }^{9}$ all patients had complex forms of malposition of the great arteries. In detail, typical TGA was present in 142 patients, a double-outlet RV was present in 27 patients, and a double-outlet LV was present in 6 patients. In 6 patients the intracardiac anatomy could not be further classified because of lack of subaortic or subpulmonary coni, unusual position and size of the VSD, and bizarre spatial relationship between the great arteries. 


$$
\begin{aligned}
& \text { Abbreviations and Acronyms } \\
& \begin{aligned}
& \text { LV }= \text { left ventricle } \\
& \text { LVOTO = } \text { left ventricular outflow tract } \\
& \text { obstruction } \\
& \text { REV }= \text { réparation à l'ètage ventriculaire } \\
& \text { RV }= \text { right ventricle } \\
& \text { RVOT = right ventricular outflow tract } \\
& \text { RVOTO= } \text { right ventricular outflow tract } \\
& \text { TGA }= \text { transtruction } \\
& \text { VSD }= \text { ventricular septal defect }
\end{aligned}
\end{aligned}
$$

Associated anomalies were found in 78\% of the patients (Table 1): 42 patients had an anomaly of the tricuspid valve, 16 patients had an anomaly of the mitral valve, and 6 patients had an anomaly of both atrioventricular valves. Conal septal anatomy was unusual in 16 patients (bilateral coni, 10 patients; no coni, 6 patients), and 26 patients did not have a welldeveloped muscular structure interposed between the semilunar valves.

\section{Previous Operation}

One hundred thirteen procedures were performed in 97 patients before the REV procedure (54\%). Most operations were concerned with improving total or effective pulmonary flow. Three patients without native LVOTO were found to have abnormalities of the pulmonary valve that precluded an arterial switch operation. Pulmonary artery banding was performed as a stage toward the REV procedure.

\section{Technique}

The technical aspects of the procedure have been extensively described $^{2-6}$ and remained relatively uniform throughout the entire experience. Resection of the conal septum, conal septal flap, and the French (Lecompte) maneuver ${ }^{2}$ were performed as indicated by the anatomy of the conal septum and tricuspid valve and the spatial relation of the great arteries. In 6 patients with absent subarterial coni no resection was required. A pericardial patch or a composite pericardial-Dacron patch was used to construct the intracardiac tunnel. The technique of right ventricular outflow tract (RVOT) repair was less consistent (Table 2); several materials were adopted for the patch and for the monocusp valve. In a limited number of patients, the segment of native aorta, excised concomitantly with the French (Lecompte) maneuver, was included in the pulmonary trunk-right ventricular anastomosis with the aim of reducing tension.

\section{Follow-up}

Ten of these patients residing in distant countries could not be traced after hospital discharge. Therefore information on survival and clinical status was available for 171 early survivors (follow-up $94.5 \%$ complete).

The mean follow-up interval was $12.3 \pm 7.1$ years. Patients were seen in the outpatient clinics of 2 institutions (Hôpital Necker, Paris, France, and Institut Jacques Cartier, Massy, France). Alternatively, local cardiologists or pediatricians were contacted. A few patients were traced and contacted directly by telephone or mail.

\section{Reoperation}

All surgical procedures involving the ventricular outlets, septa, and atrioventricular conduction abnormalities were considered reoperations. Interventional procedures, such as balloon dilatation of the RVOT, dilatation or stenting of the pulmonary arteries, or VSD device occlusion were also counted as reoperations.
TABLE 1. Associated malformations in early survivors

\begin{tabular}{lc}
\hline & No. of patients \\
\hline None & $49(27 \%)$ \\
Tricuspid valve anomaly & 42 \\
Mitral valve anomaly & 13 \\
Mitral and tricuspid valve anomaly & 6 \\
Multiple VSDs & 16 \\
Restrictive VSD & 6 \\
Pulmonary atresia & 6 \\
Pulmonary arterial branch stenosis & 21 \\
Coronary anomaly & 35 \\
Left atrial appendage juxtaposition & 19 \\
Situs inversus & 4 \\
Dextrocardia & 1 \\
IVC interruption, azygos continuation & 1 \\
Hypoplastic RV & 1 \\
\hline
\end{tabular}

$V S D$, Ventricular septal defect; $I V C$, inferior vena cava; $R V$, right ventricle.

\section{Statistical Analysis}

Survival and event-free survival estimates were obtained by using the Kaplan-Meier and cumulative incidence methods. ${ }^{10}$ The Cox proportional hazard method was used to define the association of a variable or a combination of variables with survival or adverse events.

\section{Informed Consent}

This study was approved by the institutional review board, and informed consent was obtained from each participant.

\section{RESULTS}

Overall survival at a 25-year follow-up interval was $85 \%$ by using the Kaplan-Meier method. At the same time interval, survival free of any reintervention was $45 \%$ (Figures 1 and 2).

The cumulative incidence method permits the evaluation of a single event at a given time provided that other events have not occurred. ${ }^{10}$ Figure 3 shows an analysis of 5 events at the 25-year follow-up interval: death, reoperation-free survival, and reoperation for right ventricular outflow tract obstruction (RVOTO), LVOTO, residual VSD, or other causes. The probability of reoperation-free survival, although decreasing from time zero (ie, the REV procedure) is the highest ( $45 \%$ ), followed by reoperation for RVOTO, LVOTO, residual VSD, or other causes $(33 \%, 5 \%, 6 \%$, and $6.5 \%$, respectively).

TABLE 2. Management of RVOTO

\begin{tabular}{lc}
\hline \multicolumn{1}{c}{ Patch } & No. of patients \\
\hline Dacron/pericardium & 100 \\
Other & 56 \\
Autologous aortic patch & 21 \\
Monocusp valve & \\
Heterologous pericardium & 101 \\
Autologous pericardium & 49 \\
Other & 7 \\
Valved conduit & 2 \\
\hline
\end{tabular}

RVOTO, Right ventricular outflow tract. 


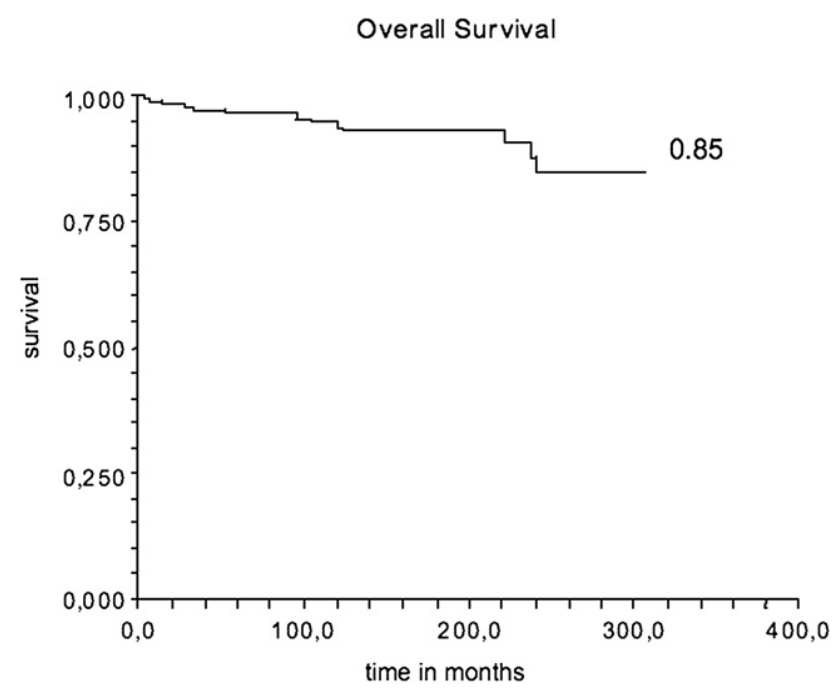

FIGURE 1. Overall survival at 25 years from surgical intervention by using the Kaplan-Meier method. Time in postoperative months is shown.

Thirteen $(7.6 \%)$ patients died late after the REV procedure. Causes of death are indicated in Table 3. Six deaths ( 4 sudden, 1 at reoperation for caval thrombosis, and 1 after a prolonged episode of supraventricular tachycardia) were caused by or triggered by an arrhythmia.

\section{Reoperation}

LV-aorta tunnel. Three patients required reoperation for relief of LVOTO; 2 of them, as mentioned above, died. One patient had an aneurysmal patch causing right ventricular obstruction; the aneurysm was resected, and the patch was replaced. In another patient the tunnel patch calcified and fractured twice, causing a recurrent VSD. The patch was completely replaced each time.

Recurrent/residual VSD. Ten patients required 12 procedures to close a recurrent or residual VSD. In one case a residual VSD was closed by means of transcatheter device implantation. Three patients received a concomitant tricuspid annuloplasty, and 3 received a pulmonary branch arterioplasty.

RVOTO/pulmonary regurgitation. This was the most frequent cause of reintervention. Table 4 indicates the procedures performed in 36 patients. The most frequently required type of reoperation was replacement of a stenotic RVOT patch with another monocusp valve-bearing patch. A valved conduit was deemed necessary in 6 patients only ( 3 of whom underwent reoperations elsewhere). On the whole, in 5 patients $(14 \%$ of those undergoing reoperations) the aim of surgical intervention was to control pulmonary regurgitation and improve the function of a dilated RV.

Right ventricular dilatation was severe in 1 child, who did not survive reoperation at another institution.

Several variables were analyzed for their possible effect on the need for reoperation on the RVOT. Three were found to increase independently the risk for reoperation: lower age at the time of the REV procedure (as a continuous variable), use of a monocusp valve made of autologous pericardium, and use of an autologous aortic segment to extend the RVOT patch. This aortic segment was often found to be calcified at reintervention.

The hazard function of reoperation for RVOTO is shown in Figure 4. The curve has a constant hazard phase that

Event Free Survival

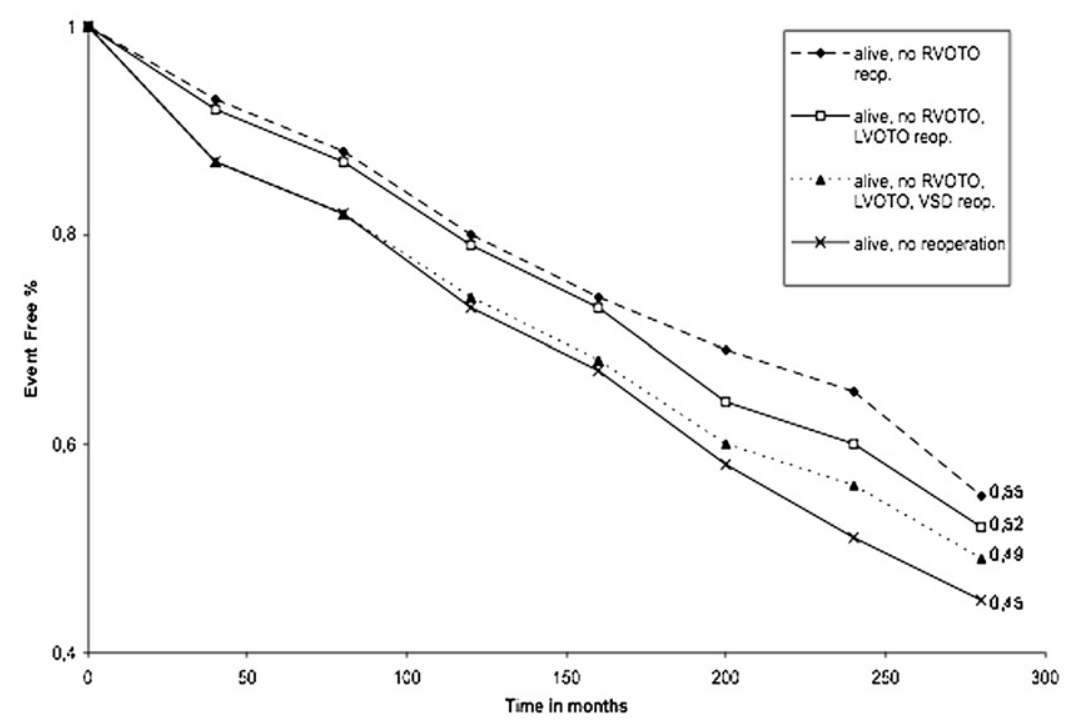

FIGURE 2. Survival free of reoperation at 25 years from surgical intervention by using the Kaplan-Meier method (see Figure 1). RVOTO, Right ventricular outflow tract obstruction; LVOTO, left ventricular outflow tract obstruction; VSD, ventricular septal defect. 


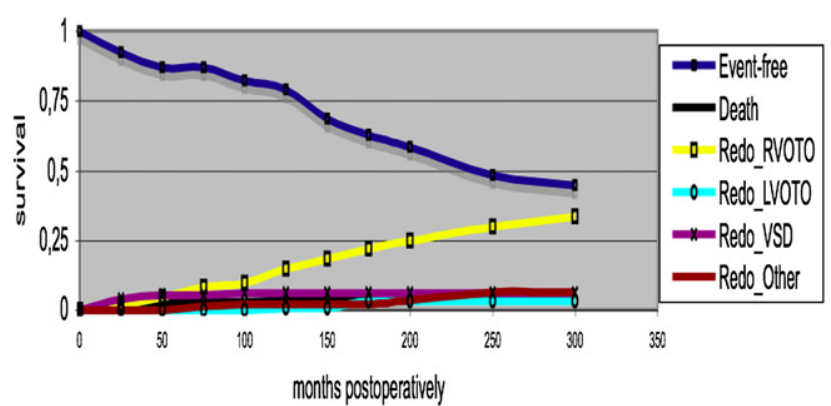

FIGURE 3. Probability of 6 different outcomes at 25 years from surgical intervention by using cumulative method analysis. The probability of survival without reintervention is $45 \%$. RVOTO, Right ventricular outflow tract obstruction; LVOTO, left ventricular outflow tract obstruction; VSD, ventricular septal defect.

suggests that the probability of reoperation does not increase over time.

\section{Clinical Status}

Most late survivors are asymptomatic (New York Heart Association class I, 137 [87\%] patients). Nineteen (12\%) patients are mildly symptomatic, with arrhythmias, dyspnea on major effort, hypertension, or noncardiac complaints (New York Heart Association class II). Two patients are severely symptomatic: 1 has important neurologic sequelae after cardiac arrest at reoperation, and 1 awaits transplantation after myocardial infarction during the REV procedure.

Thirty-one patients regularly attend school at their age level, and 11 have permanent employment. Thirty-eight patients are actively involved in sports. Five women had 6 successful pregnancies and deliveries.

\section{Reinvestigation}

An effort test was carried out in 31 patients. Results were normal in $27(87 \%)$ patients and submaximal for age in 4 patients, without evidence of arrhythmia.

Arrhythmias. One hundred thirty-one ( $72 \%$ of traced patients) patients were free of rhythm disturbances. Fourteen

TABLE 3. Causes of late death (13 patients)

\begin{tabular}{lc}
\hline & No. of patients \\
\hline At reoperation & 5 \\
LVOTO & 1 \\
LVOTO + RVOTO & 1 \\
SVT, caval thrombosis & 1 \\
Heart transplantation & 1 \\
Pulmonary regurgitation, branch stenosis & 1 \\
Sudden & 4 \\
Acute cardiac failure & 2 \\
SVT & 1 \\
Myocarditis & 1 \\
Noncardiac* & 2 \\
\hline
\end{tabular}

LVOTO, Left ventricular outflow tract; RVOTO, right ventricular outflow tract; SVT, supraventricular tachycardia. *AIDS, 1 patient; Lyme disease, 1 patient.
TABLE 4. Management of recurrent RVOTO in 36 patients

No. $(n=46$ procedures $)$

\begin{tabular}{lr}
\hline Patch replacement & 32 \\
Interventional procedure & 8 \\
Conduit implantation & 6
\end{tabular}

patients had a permanent pacemaker implanted at the time of the REV procedure for complete atrioventricular block; 5 subsequently recovered normal sinus rhythm, and 1 died of pacemaker dysfunction. Episodes of supraventricular tachycardia/flutter occurred in 7 patients, ventricular tachycardia occurred in 3 patients, and sporadic ventricular extrasystole occurred in 7 patients. One patient has first-degree atrioventricular block. Three further patients required a permanent pacemaker during follow-up.

One patient received an implantable cardioverter to treat ventricular tachycardia, and 2 had successful ablation of atrial arrhythmias. In 1 patient 3 attempts at ablation failed to control an incessant atrial tachycardia; he died of acute myocardial dysfunction.

Echocardiographic analysis. Bidimensional echocardiographic data were available for 157 patients $(92 \%$ of traced patients); they are summarized in Figure 5. In 10 (6\%) patients a systolic subaortic gradient was recorded, averaging $16.3 \pm 10.8 \mathrm{~mm} \mathrm{Hg}$. Aortic and mitral regurgitation were uncommon and usually mild: 1 patient with a major preoperative mitral anomaly has moderate mitral regurgitation. Measurements of left ventricular function (ejection fraction and shortening fraction) were available for 54 patients; they were within normal limits in $49(91 \%)$ patients, moderately decreased in 4 patients (ejection fraction, $41 \%-45 \%$ ), and severely decreased in 1 patient (awaiting heart transplantation). Invasive re-evaluation. Repeat catheterization was performed in 41 patients. In 18 cases the study was prompted by suspicion of a residual defect and heralded reoperation; 2 patients have abnormal RVOT pressure and await reoperation. Catheterization data were within normal limits for 21 $(51 \%)$ patients. However, 2 patients subsequently died, one at 116 months (arrhythmia and caval thrombosis) and the other suddenly at 2 months from the study. Three further patients underwent reoperations 59, 74, and 86 months after a normal study result.

Imaging by means of magnetic resonance or computed tomographic scanning was performed on 23 patients. Results were normal in $17(74 \%)$ patients. It was part of reevaluation toward repeat surgical intervention in 2 cases and demonstrated residual defects in 4 (3 cardiac defects and 1 thoracic defect).

\section{DISCUSSION}

Misconceptions have limited the acceptance of the REV procedure throughout the surgical constituency. It has been deemed to be technically challenging, ${ }^{11,12}$ and poorly known 


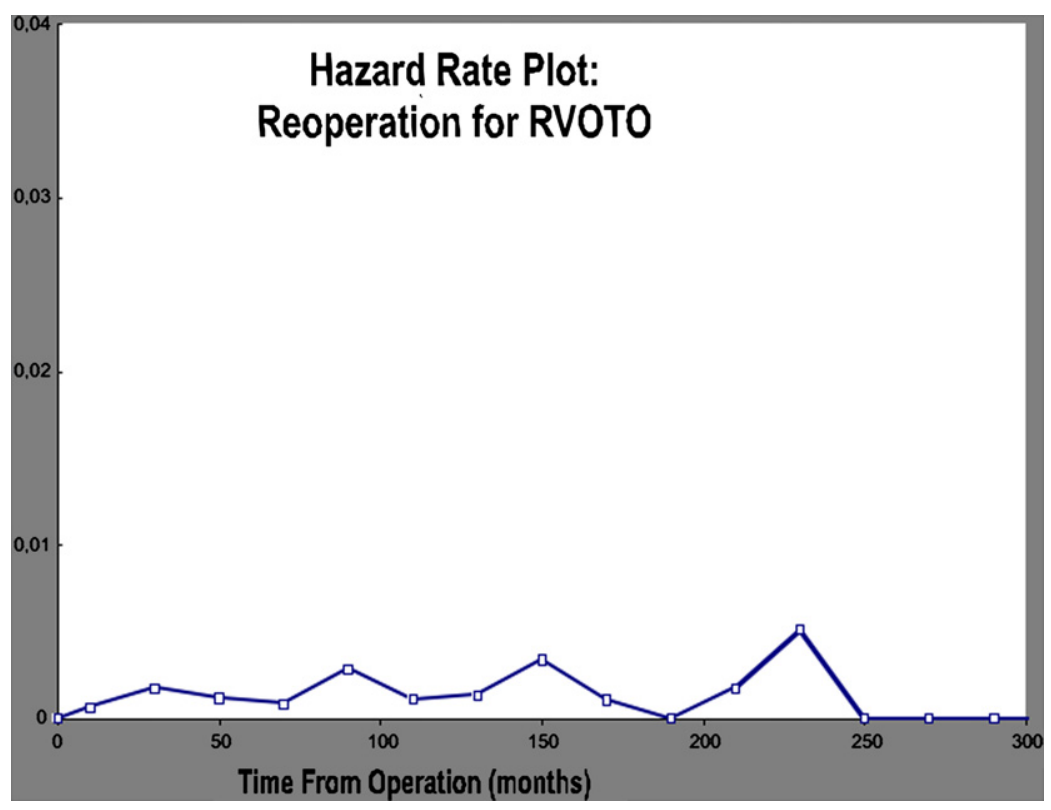

FIGURE 4. Depiction of hazard rate of reoperation for right ventricular outflow tract obstruction (RVOTO). The almost flat curve suggests that the instantaneous risk remains constant (ie, does not increase with patient's age).

long-term results. Nonetheless, from the early days, the REV procedure was applied to all sorts of anomalies of ventriculoarterial connection in addition to "classic" TGA. Patients with associated defects considered as contraindications or risk factors for the classic Rastelli operation (a total of 61 patients in this study) were not denied repair. Age constraint was not especially felt, unlike with the Rastelli operation. Our inference is that a comparison between the results described here and those of the Rastelli operation in the recent literature ${ }^{11-14}$ could be biased against the REV procedure; still, overall survival and survival free of reoperation are considerably worse than in the present series (Table 5). ${ }^{11-15}$

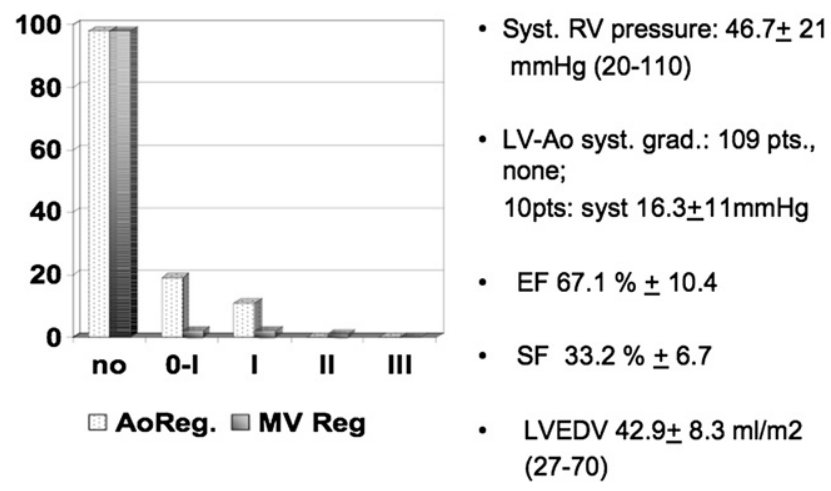

FIGURE 5. Bidimensional echocardiographic data. Syst., Systolic; $R V$, right ventricular; $L V-A o$, left ventricle-aorta; grad., gradient; $E F$, ejection fraction; $S F$, shortening fraction; $L V E D V$, left ventricular end-diastolic volume; AoReg., aortic regurgitation; $M V$ Reg, mitral valve regurgitation; 2-D, 2-dimensional.
Dearani and coworkers ${ }^{14}$ focused on the problem of reoperation for recurrent RVOTO. Their late incidence of LVOTO was low because of liberal use of VSD enlargement. Ideal age at repair remained unspecified. There was a high prevalence of late cardiac/sudden deaths (38/160 [24\%] early survivors), but the authors believed that the Rastelli operation remains the preferred repair for this subset of patients. Conversely, Kreutzer and colleagues ${ }^{11}$ consider their late results with the Rastelli operation disappointing in comparison with atrial, arterial, and even Fontan repairs. Recurrent RVOTO and LVOTO, as well as sudden death, constituted serious problems. They infer that the Rastelli operation should be reserved for patients with severe "mechanical" native LVOTO, whereas patients with "dynamic" (or resectable) LVOTO ${ }^{16}$ are perhaps better served by an arterial switch operation and VSD closure in the first year of life. We do not disagree with this line of thought but note that a large percentage of patients with TGA or malposition of the great arteries, VSD, and LVOTO have complex forms of obstruction not amenable to resection and marked pulmonary valve hypoplasia ${ }^{17-20}$ or even pulmonary atresia. A recent anatomic study ${ }^{20}$ brings support to the hypothesis of Kreutzer and colleagues ${ }^{11}$; unfortunately, early and late results in patients with pulmonary valve hypoplasia at the arterial switch operation seem worse than expected from an arterial switch operation with a "normal" native pulmonary valve. Emani and associates ${ }^{21}$ reviewed their results with 3 techniques in patients with TGA and LVOTO: arterial switch operation alone, arterial switch operation and LVOT repair, and non-arterial switch operation repair (Rastelli or Nikaidoh procedures). The isolated arterial switch 
TABLE 5. Overall survival and prevalence of reoperation for recurrent RVOTO: Comparison with literature data

\begin{tabular}{llrr}
\hline \multicolumn{1}{c}{ Source } & Procedure & $\begin{array}{c}\text { Twenty-year overall } \\
\text { survival }\end{array}$ & $\begin{array}{c}\text { Fifteen-year freedom } \\
\text { from RVOT reoperation }\end{array}$ \\
\hline Great Ormond Street Hospital, London (1981), ${ }^{13} 41$ patients (1971-1978) & Rastelli & $58 \% *, \dagger$ & $52 \% \ddagger$ \\
Children's Hospital, Boston (2000), ${ }^{11}$ 94 patients (1973-1998) & Rastelli & $59 \%$ & $20 \%$ \\
Mayo Clinic, Rochester (2001), ${ }^{14} 160$ patients (1968-1990) & Rastelli & $58 \%$ & $29 \%$ \\
German Heart Center (2007), ${ }^{2} 39$ patients (1977-2004) & Rastelli & $32 \%$ & $64 \%$ \\
University of Texas, Dallas (2007), ${ }^{15} 18$ patients (1983-2006) & Bex-Nikaidoh & $95 \%$ & $75 \%$ \\
This series, 171 patients (1980-2003) & REV procedure & $85 \%$ & \\
\hline
\end{tabular}

RVOTO, Right ventricular outflow tract obstruction. *Eight-year survival. † Including early mortality $(=10 \%)$. †̇Including early mortality $(=7 \%)$.

operation and Rastelli operation had the highest incidence of reintervention for recurrent/residual LVOTO.

Reoperation caused by LVOTO was rare in our series (3 patients) because a large LV-aorta connection was created as a result of the resection of the conal septum and the use of a shorter and straight patch. Conversely, anterior VSD enlargement is usually recommended for the Rastelli operation. $^{11,12,14}$

Reoperation for RVOTO was necessary in a certain number of our patients, some of whom required multiple procedures. Even so, comparison of our data with those of the Rastelli operation clearly demonstrates a much lower prevalence of this complication (Table 5). Moreover, the hazard function of reoperation for RVOTO after the REV procedure remains constant over time. We were unable to find similar data regarding the Rastelli operation or conduit operations in the literature, but intuitively, the instantaneous risk of reoperation in this category of patients will increase with time because of a worsening patient-conduit mismatch and progressive conduit degeneration.

In this series lower age at the time of the operation as a continuous variable (with a cutoff point at 22 months) and 2 technical modifications stood out as independent risk factors for repeat operations because of RVOTO. Although faulty techniques must be abandoned, the ideal age at the time of the operation remains elusive. Ninetythree $(45 \%)$ patients in this series were younger than 2 years at the time of the operation.

The problem is also unsolved with the Rastelli operation. It has been suggested that an early Rastelli operation would achieve better long-term results by avoiding the negative effects of long-standing cyanosis and ventricular overload. A trend toward higher early surgical mortality and the concern for multiple reoperations might discourage most units from adopting this policy, as has occurred in the past.

Unlike patients with tetralogy of Fallot, ${ }^{22}$ pulmonary insufficiency caused by the time-limited function of the monocusp valve has not emerged as a frequent cause for reoperation. In 30 of 33 patients who underwent reoperations performed by our group, the original patch was simply replaced by a monocusp valve bearing a polytetrafluoroethylene patch tailored by a ring-reinforced tubular prosthesis (PTFE Stented tubular graft; W.L. Gore \& Associates, Inc, Flagstaff, Ariz). On a mean follow-up time interval of more than 12 years, patients having undergone the REV procedure seem to tolerate pulmonary insufficiency remarkably well. We can only speculate on the reason for such a favorable course. The straight, short tunnel patch (producing a limited bulge in the right ventricular cavity) and the resection of the conal septum, rather than VSD anterosuperior enlargement, might favorably affect both left and right ventricular function. Left ventricular function is not as good after a Rastelli operation. ${ }^{22}$

Dissatisfaction with the Rastelli operation ${ }^{23}$ recently revived interest in the operation originally described by Bex and coworkers in $1980^{24}$ and adopted by Nikaidoh in 1984. ${ }^{15}$ This complex procedure, termed "aortic translocation" borrows steps from the arterial switch operation, Rastelli operation, REV procedure, and Ross operation. It is logical to anticipate complications inherent to all these procedures, such as coronary distortion, aortic valve regurgitation, and recurrent RVOTO. Uncertainty still exists about whether to translocate the coronary artery or arteries, and at times this has been done at the completion of the procedure because of evidence of myocardial ischemia.

Moderate aortic insufficiency was reported by Morell ${ }^{25}$ in 3 of 11 survivors; one of them eventually required aortic valve replacement. ${ }^{26}$ Moderate aortic insufficiency was also observed in 1 of 11 patients by Bautista-Hernandez and colleagues, ${ }^{27}$ and mild aortic insufficiency was found in 8 of 18 survivors by Yeh and associates. ${ }^{28}$

In these 3 series the median follow-up intervals were 33 months, 59 months, and 11 years, respectively. On the whole, 15 reoperations for conduit replacement were required on 40 early survivors. Atrial and ventricular arrhythmias also occurred, requiring a maze procedure in one case and an implantable defibrillator in another. The authors were compelled to make this choice by the need to solve the problem of LVOTO after the Rastelli operation. In our study of a large series of patients with a long follow-up interval, we have shown that LVOTO rarely occurs.

In a recent article $\mathrm{Hu}$ and coworkers ${ }^{26}$ compared the Rastelli operation, the REV procedure, and the Bex-Nikaidoh 
procedure performed randomly on 30 patients. They modified both the REV procedure and the Bex-Nikaidoh procedure by adding total pulmonary valve translocation to the original techniques. All patients $(n=11)$ undergoing the modified Bex-Nikaidoh procedure survived, whereas 2 patients died after the REV procedure and 1 after the Rastelli operation.

The follow-up interval is less than 12 months in each surgical group; there were no reoperations or sudden deaths. One patient in the Bex-Nikaidoh group has mild aortic insufficiency, and 9 have a degree of pulmonary insufficiency, as do 5 after the REV procedure. It is apparent, even with such a short follow-up interval, that the modification of the technique has not yielded the desired result of avoiding pulmonary regurgitation. Moreover, 1 patient in the BexNikaidoh group shows early evidence of aortic regurgitation. In our opinion neither the Bex-Nikaidoh procedure nor its ingenious modifications have yet produced clear evidence of results superior to those of the REV procedure.

\section{Limitations of the Study}

The nature of the study is retrospective. Although a large series of patients was analyzed, emphasis was put on the use of a unique procedure rather than on patient diagnosis. Patients in some anatomic subgroups could have a better probability of early and long-term survival than those with classic TGA who were treated with the Rastelli operation in the compared series. Clinical status was generally good, but complete noninvasive imaging and functional studies were performed in a limited number of late survivors.

\section{CONCLUSIONS}

Although of enormous historical value as the first successful step toward anatomic repair of TGA, the value of the classic Rastelli operation is presently reduced by the recognition that alternative options exist. We describe the excellent results obtained with the REV procedure, which obviates many contraindications of the Rastelli operation. Because its performance does not contemplate a prosthetic conduit, it can be safely applied to infants and small children, thus avoiding multiple palliative steps. Recurrent LVOTO is exceptional, and recurrent right ventricular obstruction is less common and shows a constant hazard curve. Ventricular function and clinical status are excellent in the majority of survivors. If a search for alternatives is at all justified, we strongly suggest that survival, incidence of complications, need for reoperation, and ventricular performance of "new" procedures be compared with those of the REV procedure and not with the Rastelli operation.

We gratefully acknowledge the work of Sara Swartz in reviewing the manuscript.

\section{References}

1. Rastelli GC. A new approach to "anatomic" repair of transposition of the great arteries. Mayo Clin Proc. 1969;44:1-12.

2. Lecompte Y, Neveux JY, Leca F, Zannini L, Tu TV, Duboys L, et al. Reconstruction of the pulmonary outflow tract without a prosthetic conduit. J Thorac Cardiovasc Surg. 1982;84:727-33.

3. Rubay J, Lecompte Y, Batisse A, Durandy Y, Dibie A, Lemoine G, et al. Anatomic repair of anomalies of ventriculo-arterial connection (REV). Eur J Cardiothorac Surg. 1988;2:305-11.

4. Lecompte Y. Réparation à l'étage ventriculaire-the REV procedure: technique and clinical results. Cardiol Young. 1991;1:63-70.

5. Vouhé PR, Tamisier D, Leca F, Ouaknine R, Vernant F, Neveux JY. Transposition of the great arteries, ventricular septal defect and pulmonary outflow tract obstruction: Rastelli or Lecompte procedure? J Thorac Cardiovasc Surg. 1992; 103:428-36.

6. Lecompte Y, Vouhé P. Réparation à l'Etage ventriculaire (REV procedure): not a Rastelli procedure without conduit. Op Tech Thorac Cardiovasc Surg. 2003; 3:150-9.

7. Lecompte Y. Rastelli repair for transposition of the great arteries: still the best choice? J Thorac Cardiovasc Surg. 2002;123:192-3.

8. Lee JR, Lim HG, Kim YJ, Rho JR, Bae EJ, Noh CI, et al. Repair of transposition of the great arteries, ventricular septal defect and left ventricular outflow tract obstruction. Eur J Cardiothorac Surg. 2004;25:735-41

9. Sidi D, Lecompte Y. Transposition and malposition of the great arteries with ventricular septal defect. In: Hoffman JIE, Moller JH, eds. Structural heart disease. 1st ed. Philadelphia, Pa: Churchill Livingstone; 2000:363-73.

10. Gooley TA, Leisenring W, Crowley J, Storer BE. Estimation of failure probabilities in the presence of competing risks: new representation of old estimators. Stat Med. 1999;18:695-706.

11. Kreutzer C, De Vive J, Oppido G, Kreutzer J, Gauvreau K, Freed M, et al. Twenty-five-year experience with Rastelli repair for transposition of the great arteries. J Thorac Cardiovasc Surg. 2000;120:211-23.

12. Hörer J, Schreiber C, Dworak E, Cleuziou J, Prodan Z, Vogt M, et al. Long-term results after the Rastelli repair for transposition of the great arteries. Ann Thorac Surg. 2007;83:2169-75.

13. Moulton AL, de Leval MR, Macartney FJ, Taylor JFN, Stark J. Rastelli procedure for transposition of the great arteries, ventricular septal defect and left ventricular outflow train 41 patients (1971 obstruction: early and late results in 41 patients (1971 to 1978). Br Heart J. 1981;45:20-8.

14. Dearani JA, Danielson GK, Puga FJ, Mair DD, Schleck CD. Late results of the Rastelli operation for transposition of the great arteries. Semin Thorac Cardiovasc Surg Pediatr Card Surg Annu. 2001;4:3-15.

15. Nikaidoh $\mathrm{H}$. Aortic translocation and biventricular outflow tract reconstruction: a new surgical repair for transposition of the great arteries with a ventricular septal defect and pulmonary stenosis. J Thorac Cardiovasc Surg. 1984;88:365-72.

16. Yacoub MH, Arensman FW, Keck E, Radley-Smith R. Fate of dynamic left ventricular outflow tract obstruction after anatomic correction of transposition of the great arteries. Circulation. 1983;68(suppl II):56-62.

17. Sansa M, Tonkin IL, Bargeron LM Jr, Elliott LP. Left ventricular outflow tract obstruction in transposition of the great arteries: an angiographic study of 74 cases. Am J Cardiol. 1979;44:87-95.

18. Moene RJ, Oppenheimer-Dekker A. Congenital mitral valve anomalies in transposition of the great arteries. Am J Cardiol. 1982;49:1972-8.

19. Hazekamp M, Portela F, Bartelings M. The optimal procedure for transposition of the great arteries and left ventricular outflow tract obstruction: An anatomical study. Eur J Cardiothorac Surg. 2007;31:879-87.

20. Soo Park C, Seo D-M, Park J-J, Hwue Kim Y, Park I- S. The significance of pulmonary annulus size in the surgical management of transposition of the great arteries with ventricular septal defect and pulmonary stenosis. J Thorac Cardiovasc Surg. 2010;139:135-8.

21. Emani SM, Beroukhim R, Zurakowski D, Pigula FA, Mayer JE Jr, del Nido PJ, et al. Outcomes after anatomic repair for d-transposition of the great arteries with left ventricular outflow tract obstruction. Circulation. 2009; 120(suppl 1):S53-8.

22. Hanley FL. Editorial: management of the congenitally abnormal right ventricular outflow tract-What is the right approach? J Thorac Cardiovasc Surg. 2000;119:1-3.

23. Graham TP Jr, Franklin RCG, Wyse RKH, Gooch V, Deanfield JE. Left ventricular wall stress and contractile function in transposition of the great arteries after the Rastelli operation. J Thorac Cardiovasc Surg. 1987;93:775-84.

24. Bex JP, Lecompte Y, Baillot F, Hazan E. Anatomical correction of transposition of the great arteries. Ann Thorac Surg. 1980;29:86-9. 
25. Morell VO, Jacobs JJ, Quintessenza JA. Aortic translocation in the management of transposition of the great arteries with ventricular septal defect and pulmonary stenosis: results and follow-up. Ann Thorac Surg. 2005;79: 2089-93.

26. Hu S-S, Liu Z-G, Li S-J, Shen X-D, Xu W, Liu J-P, et al. Strategy for biventricular outflow tract reconstruction: Rastelli, REV or Nikaidoh procedure? J Thorac Cardiovasc Surg. 2008;135:331-8.
27. Bautista-Hernandez V, Marx GR, Bacha EA, del Nido PJ. Aortic root translocation plus arterial switch for transposition of the great arteries with left ventricular outflow tract obstruction. Intermediate-term results. J Am Coll Cardiol. 2007;49: 485-90.

28. Yeh T Jr, Ramaciotti C, Leonard SR, Roy L, Nikaidoh H. The aortic translocation procedure: mid term results superior to the Rastelli procedure. $J$ Thorac Cardiovasc Surg. 2007;133:461-9.

Access to The Journal of Thoracic and Cardiovascular Surgery Online is reserved for print subscribers!

Full-text access to The Journal of Thoracic and Cardiovascular Surgery Online is available for all print subscribers. To activate your individual online subscription, please visit The Journal of Thoracic and Cardiovascular Surgery Online, point your browser to http://www.mosby.com/itcvs, follow the prompts to activate your online access, and follow the instructions. To activate your account, you will need your subscriber account number, which you can find on your mailing label (note: the number of digits in your subscriber account number varies from 6 to 10). See the example below in which the subscriber account number has been circled:

\section{Sample mailing label}

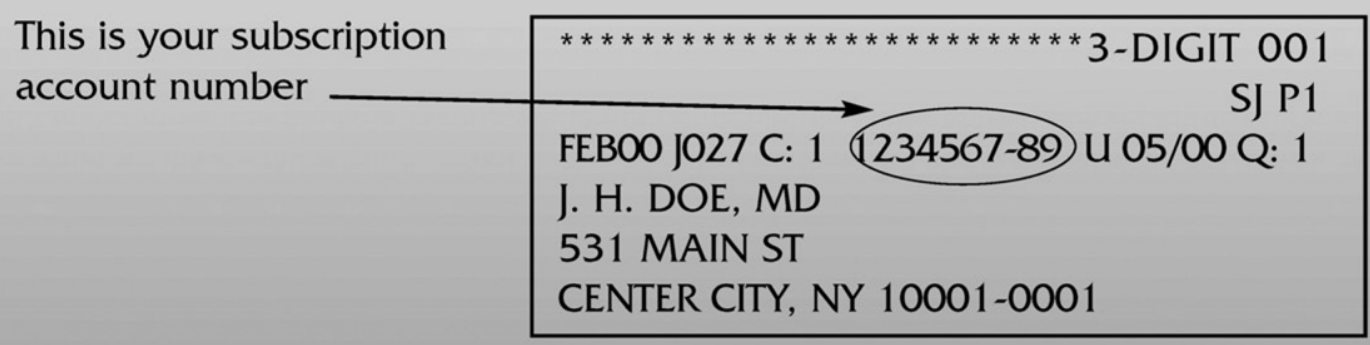

Personal subscriptions to The Journal of Thoracic and Cardiovascular Surgery Online are for individual use only and may not be transferred. Use of The Journal of Thoracic and Cardiovascular Surgery Online is subject to agreement to the terms and conditions as indicated online. 